\title{
Comparison of numerical schemes of river flood routing with an inertial approximation of the Saint Venant equations
}

\section{Comparação de esquemas numéricos de propagação de vazão com aproximação inercial das equações de Saint Venant}

\author{
Alice César Fassoni-Andrade ${ }^{1}$, Fernando Mainardi Fan ${ }^{1}$, Walter Collischonn ${ }^{1}$, Artur César Fassoni ${ }^{2}$ and \\ Rodrigo Cauduro Dias de Paiva ${ }^{1}$ \\ ${ }^{1}$ Universidade Federal do Rio Grande do Sul, Porto Alegre, RS, Brasil \\ ${ }^{2}$ Universidade Federal de Itajubá, Itajubá, MG, Brasil \\ E-mails: alice.fassoni@ufrgs.br (ACFA),fernando.fan@ufrgs.br (FMF), collischonn@iph.ufrgs.br (WC), fassoni@unifei.edu.br (ACF), \\ rodrigocdpaiva@gmail.com (RCDP)
}

Received: May 08, 2017 - Revised: October 15, 2017 - Accepted: December 10, 2017

\begin{abstract}
The one-dimensional flow routing inertial model, formulated as an explicit solution, has advantages over other explicit models used in hydrological models that simplify the Saint-Venant equations. The main advantage is a simple formulation with good results. However, the inertial model is restricted to a small time step to avoid numerical instability. This paper proposes six numerical schemes that modify the one-dimensional inertial model in order to increase the numerical stability of the solution. The proposed numerical schemes were compared to the original scheme in four situations of river's slope (normal, low, high and very high) and in two situations where the river is subject to downstream effects (dam backwater and tides). The results are discussed in terms of stability, peak flow, processing time, volume conservation error and RMSE (Root Mean Square Error). In general, the schemes showed improvement relative to each type of application. In particular, the numerical scheme here called Prog $Q(k+1) \times Q(k+1)$ stood out presenting advantages with greater numerical stability in relation to the original scheme. However, this scheme was not successful in the tide simulation situation. In addition, it was observed that the inclusion of the hydraulic radius calculation without simplification in the numerical schemes improved the results without increasing the computational time.
\end{abstract}

Keywords: Inertial model; Numerical stability; Computational time; HEC-RAS.

\section{RESUMO}

O modelo inercial unidimensional de propagação de vazão, formulado através de uma solução explícita, possui resultados comparáveis aos modelos que consideram as equações completas de Saint-Venant. A principal vantagem é a simplicidade na formulação com bons resultados. No entanto, o modelo inercial está restrito à um passo de tempo pequeno para evitar instabilidade numérica. Este trabalho propõe seis esquemas numéricos que modificam o modelo inercial unidimensional buscando aumentar a estabilidade numérica da solução. O desempenho dos esquemas numéricos propostos foi comparado em quatro situações de declividade do rio (normal, baixa, alta e muito alta) e em duas situações onde o rio está sujeito ao efeito de jusante (remanso e maré). O modelo hidrodinâmico HEC-RAS foi utilizado para validação das soluções. Os resultados são discutidos em termos de estabilidade, vazão de pico, tempo de processamento, erro de conservação de volume e raiz do erro médio quadrático da vazão (Root Mean Square Error - RMSE). De forma geral os esquemas mostraram melhora relativa a cada tipo de aplicação. Em particular, o esquema numérico aqui denominado Prog $Q(k+1) \times Q(k+1)$ se destacou apresentando vantagens com maior estabilidade numérica em relação ao esquema original. Porém este esquema não foi bem sucedido na situação de simulação com maré. Além disso, observou-se que a inclusão do cálculo do raio hidráulico sem simplificação nos esquemas numéricos melhorou os resultados sem aumentar o tempo computacional.

Palavras-chave: Modelo inercial; Estabilidade numérica; Tempo computacional; HEC-RAS. 


\section{INTRODUCTION}

River's flow and the propagation of flood waves can be represented by hydrodynamic models that solve numerically the Saint-Venant equations. These are formed by the continuity equation (Equation 1), which represents the mass conservation, and by the dynamic equation (Equation 2), which represents the forces acting on the flow (CUNGE; HOLLY; VERWEY, 1980; TUCCI, 2005). The two equations are presented considering a one-dimensional flow.

$$
\frac{\partial h}{\partial t}+\frac{\partial Q}{B . \partial x}=0
$$

$$
\underbrace{\frac{\partial Q}{\partial t}}_{1}+\underbrace{\frac{\partial\left(Q^{2} / A\right)}{\partial x}}_{2}=\underbrace{-g A \frac{\partial h}{\partial x}}_{3}+\underbrace{g A S_{0}}_{4}-\underbrace{g A S_{f}}_{5}
$$

where, $Q$ is the flow, $h$ is the water depth, $t$ is the time, $B$ is the cross-section width, $x$ is the longitudinal distance, $g$ is the gravitational acceleration, $A$ is the cross-section area, $S_{0}$ is the bed slope, and $S_{f}$ is the friction slope.

The left side of the dynamic equation (Equation 2) refers to the local inertial (1) and advective inertial terms (2). The right side represents the external and internal forces acting on the fluid: pressure (3), weight (4) and friction (5).

The Saint-Venant equations can be simplified by eliminating some terms of the dynamic equation, which result in benefits for the models such as simpler formulation, more accessible programming codes, and gain in computational efficiency. For example, Kinematic Wave, Muskingum and Muskingum-Cunge models (CUNGE, 1969; FREAD, 1993; CHANSON, 2004) consider only the terms of weight (4) and friction (5). These terms have a greater contribution to the flow acceleration than other (NÉELZ; PENDER, 2009). The Muskingum-Cunge model is often used as a flow propagation module in rainfall-runoff models (TUCCI, 2005; BEVEN, 2011). However, the traditional linear Muskingum-Cunge method does not adequately represent the flow in some situations where the flood wave celerity is not constant, or in situations with the backwater effect (PONCE, 1989).

Another simplification, considered slightly more complete than Kinematic Wave, Muskingum and Muskingum-Cunge models, is the result of using only the terms of pressure (3), weight (4) and friction (5), called non-inertial (YEN; TSAI, 2001) and diffusion wave models (YEN; TSAI, 2001; CHANSON, 2004). The diffusion wave model has the advantage of representing more adequately the attenuation of a flood wave propagating downstream. However, it has limitations in comparison with the complete Saint-Venant equations, as in representation of downstream effects (MONTERO et al., 2013).

The inertial model, or local inertial, disregards only the advective inertial term (2). This model, popularized by Bates, Horritt and Fewtrell (2010), was widely applied to represent two-dimensional flow in flood areas (NEAL et al., 2011; ALMEIDA et al., 2012; ALMEIDA; BATES, 2013). Montero et al. (2013) demonstrated that the inertial model has advantages over the diffusion wave model when compared to complete solutions of the Saint-Venant equation. Fan et al. (2014) tested the inertial formulation for representing one-dimensional flow in rivers. The authors showed their applicability in scenarios with high and low rivers' slope and subjected to downstream effects, such as backwater and tide. The results were comparable to the complete Saint-Venant equations. However, it was also observed that the model presents numerical instability for values of the Courant number much smaller than 1 (the stability condition requires that $\sqrt{g h} \frac{\Delta t}{\Delta x}$ must be smaller than 1). Furthermore, Monteiro et al. (2015) tested the inertial solution for the simulation of waves caused by the closure of floodgates, and also obtaining results comparable to the complete solutions of the Saint-Venant equations.

The main advantage of the inertial model is the easy implementation with simple code and good results in relation to the solution of the Saint-Venant equations. As a result, the model has been used in hydrological models and flood models by several authors (DOTTORI; TODINI, 2011; NEAL; SCHUMANN; BATES, 2012; ALMEIDA; BATES, 2013; COULTHARD et al., 2013; YAMAZAKI; ALMEIDA; BATES, 2013; SAMPSON et al., 2015). In Brazil, the authors Pontes et al. $(2015,2017)$ presented coupling of the one-dimensional inertial model in a large-scale hydrological model (MGB-IPH). The authors pointed out that with this model it is possible to perform site simulations, as in floodplains, more adequately than when using other simplified methods. They showed that the scheme has robustness in coupling with hydrological models and, in addition, the parallel processing is easy.

As commented, several studies point to the inertial model as an alternative to the complete solution of the Saint-Venant equations and to other simplified models representing the one-dimensional flow. However, alternatives to improve the model's numerical stability may still be explored. Therefore, this paper proposes and tests some changes in the inertial formulation in order to improve the numerical stability. The numerical scheme of the one-dimensional inertial model, as applied by Fan et al. (2014), was altered in relation to the approximation of the numerical derivative, in relation to the numerical method and also in relation to the dynamic equation's friction term (term 5 in Equation 2). Six new schemes were proposed and tested considering the hydraulic radius without simplification $(R \approx h B /(2 . h+B))$ and six numerical schemes with hydraulic radius simplification $(R \approx h)$.

The performance of the schemes was compared with original scheme, presented by Bates, Horritt and Fewtrell (2010), and with the complete solution of the Saint Venant equations (HEC-RAS hydrodynamic model - USACE, 2016), i.e. the HEC-RAS model was considered the "true solution" in tests. This model solves the equations by an implicit finite difference scheme described in USACE (2016). For the sake of isonomy with the knowledge already generated and published on the one-dimensional inertial model application, scenarios identical to those used by Fan et al. (2014) were considered. The scenarios were: four situations of river's slope (normal, low, high and very high) and two situations where the river is subject to downstream effect (backwater and tide). 


\section{ONE-DIMENSIONAL INERTIAL MODEL}

The dynamic equation (Equation 2) in the one-dimensional inertial model is rewritten (Equation 3) considering a rectangular river cross-section, representing the pressure and weight forces in terms of water surface level $(y)$ and estimating the friction force using the Manning equation,

$$
\frac{\partial Q}{\partial t}+g B h \frac{\partial y}{\partial x}+g \frac{|Q| Q n^{2}}{B h R^{4 / 3}}=0
$$

where $y$ is the water surface level, $n$ is the Manning roughness coefficient, $R$ is the hydraulic radius.

The hydraulic radius is approximated by the depth $(R \approx h)$, considering that the rivers cross sections have a width much larger than the depth. The derivatives of the dynamic equation are approximated by a numerical scheme of progressive finite differences in space and time, which results in Equation 4, as presented in Fan et al. (2014).

$$
\frac{Q_{i+\frac{1}{2}}^{k+1}-Q_{i+\frac{1}{2}}^{k}}{\Delta t}+g \cdot B \cdot h_{i+\frac{1}{2}}^{k} \cdot \frac{y_{i+1}^{k}-y_{i}^{k}}{\Delta x}+g \cdot \frac{\left|Q_{i+\frac{1}{2}}^{k}\right| \cdot Q_{i+\frac{1}{2}}^{k+1} \cdot n^{2}}{B \cdot\left(h^{k}{ }_{i+\frac{1}{2}}\right)^{7 / 3}}=0
$$

Where $i$ and $k$ are the indices in space and time, respectively. $\Delta x$ is the length of the channel section (m).

The $h_{i+\frac{1}{2}}^{k}$ term is the depth in the contour of the channel stretch $(\Delta x)$ and can be estimated by the difference of the maximum value of the water level $(y)$ and the maximum value of the bottom level $(z)$ in the center of the channel stretch, according to Equation 5.

$$
\underset{i+\frac{1}{2}}{h^{k}}=\max \left[y_{i}^{k} ; y_{i+1}^{k}\right]-\max \left[z_{i} ; z_{i+1}\right]
$$

From the explicit solution of Equation 4, the flow is estimated at each time step according to Equation 6. Bates, Horritt and Fewtrell (2010) considered the multiplication of the flow in time step $k$ by the flow in time step $k+1$ in friction term $\left(\left|Q_{i+\frac{1}{2}}^{k}\right| Q_{i+\frac{1}{2}}^{k+1}\right)$ to increase the stability of the numerical scheme.

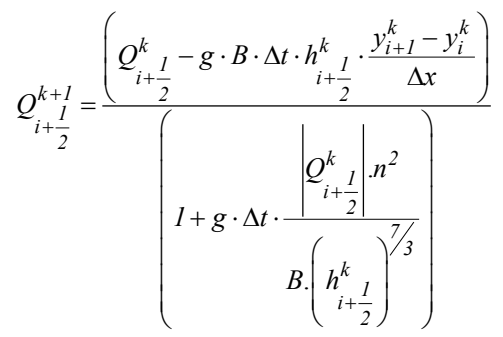

Based on the flow values $\left(Q_{i+\frac{1}{2}}^{k+1}\right)$, the continuity equation (Equation 1), discretized by a spatial and time progressive scheme (Equation 7), is applied to estimate the depth at all reaches $i$ at the end of the time interval $(k+1)$. From this value, the water level at the end of the time interval is computed by Equation 8 .

$$
h_{i}^{k+1}=h_{i}^{k}-\frac{\Delta t}{B \cdot \Delta x}\left(Q_{i+\frac{1}{2}}^{k+1}-Q_{i-\frac{1}{2}}^{k+1}\right)
$$

$y_{i}^{k+1}=z_{i}+h_{i}^{k+1}$

Equation 6 requires the initial values of the depth $\left(h_{0}\right)$ and the water level $\left(y_{0}\right)$ in all reaches. For this, the same initial flow is assumed in all reaches and the depth is calculated by considering the continuous and uniform flow, that is, the Manning equation with simplification of the hydraulic radius $(R \approx h)$. In addition, boundary conditions are required in the first and last channel stretch. The typical upstream condition is a flow hydrograph and the downstream condition can be a rating curve or a normal depth.

The numerical scheme is restricted to the size of time step $(\Delta \mathrm{t})$ and channel stretch $(\Delta \mathrm{x})$ to avoid numerical instability. Thus, the choice of $\Delta \mathrm{t}$ and $\Delta \mathrm{x}$ must respect the Courant-Friedrichs-Levy condition (Courant number $-C$ ), given by Equation 9 .

$C=\sqrt{g h} \frac{\Delta t}{\Delta x}$ where $C \leq 1$

The depth (h) used in this calculation corresponds to the largest depth found in the river reach. Although this condition requires a value less than 1, Bates, Horritt and Fewtrell (2010) observed that the value must be less than 0.7 to ensure the numerical scheme stability in two-dimensional simulations.

After the initial development of the model, Almeida et al. (2012) proposed a modification in the numerical scheme to improve stability in low friction situations, such as in urban areas. In the new scheme, a weighting $(\theta)$ was introduced in the flow derivative in relation to the time. Thus, the flow value at time $\mathrm{k}$ and reach $i+\frac{1}{2}$ is weighted considering the flow at time $\mathrm{k}$ and in the reach $i+\frac{1}{2}, i-\frac{1}{2}$, and $i+\frac{3}{2}$, according to Equation 10.

$\frac{\partial Q}{\partial t}=\frac{Q_{i+\frac{1}{2}}^{k+1}-\left(\theta \cdot Q_{i+\frac{1}{2}}^{k}+\frac{(1-\theta)}{2} \cdot\left(Q_{i-\frac{1}{2}}^{k}+Q_{i+\frac{3}{2}}^{k}\right)\right)}{\Delta t}$

The weighting $(\theta)$ varies from 0 to 1 . Using Equation 10 to approximate the numerical derivative, the flow in each time step in the new scheme is estimated according to Equation 11.

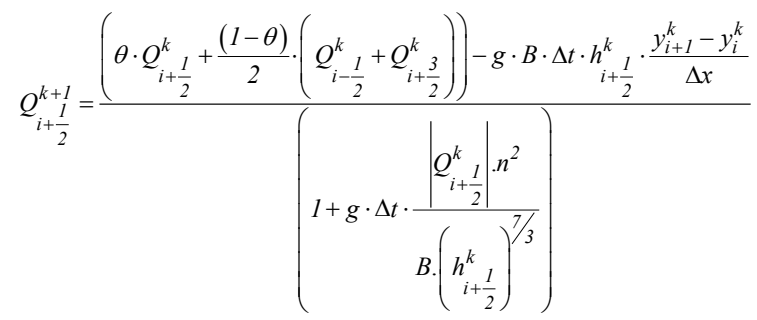


According to Almeida et al. (2012), the inclusion of the weighting allowed more stability in simulations performed by the authors.

\section{MODIFICATIONS PROPOSED TO THE NUMERICAL SCHEME OF THE INERTIAL MODEL}

In the inertial model formulation proposed by Bates, Horritt and Fewtrell (2010), the flow at time step $k+1$ (Equation 6) is solved by the Euler method, i.e. a first order method where the first derivative provides a direct estimate of the slope for entire interval $(\Delta \mathrm{t})$. In this method, the global truncation error is proportional to the time step size (CHAPRA; CANALE, 2012). The second-order Runge-Kutta method (RK2), equivalent to the Heun method without iteration, and the fourth-order Runge-Kutta method (RK4) are more accurate because the errors are of the order of $\Delta t^{2}$ and $\Delta t^{4}$, respectively (CHAPRA; CANALE, 2012). Thus, the reduction of the step size decreases the error at a faster rate than in the Euler method (CHAPRA; CANALE, 2012). Another way to improve the accuracy is to use a centered derivative (Cent) instead of the progressive derivative (Prog). This derivative allows a second-order approximation, with an error of the order of $\Delta t^{2}$.

In this paper, the modifications of the numerical schemes were done in the derivative approximation (Prog and Cent), in the numerical method (Euler, RK2 ou RK4) and also in the friction term (Equation 2), specifically in the time index $(k)$ of the flow $\left(\left|Q_{i+\frac{1}{2}}^{k}\right| Q_{i+\frac{1}{2}}^{k+1}\right)$.

The properties of the proposed numerical schemes, such as convergence, consistency and stability, were not evaluated. These analyzes indicate how close the numerical scheme is to the analytical solution, and if the errors are not amplified (POPESCU, 2014). Thus, the numerical schemes were only tested and evaluated in different numerical applications. In each test, 16 simulations were run, each one with the methods listed in Table 1 and described in detail below (" $\mathrm{R}$ " means that the hydraulic radius was not simplified).

\section{Scheme $Q(k+1) \times Q(k-1)$ :}

The first modification made in the original numerical scheme was to approximate the flow by a time-centered derivative, which considers the flow in the time steps $k+1$ and $k-1$. Thus, the proposed scheme also considered the flow in these time steps in the friction term $\left(\left|Q_{i+\frac{1}{2}}^{k-1}\right| Q_{i+\frac{1}{2}}^{k+1}\right)$. Rearranging, the flow $Q_{i+\frac{1}{2}}^{k+1}$ is estimated directly by Equation 12 . This scheme will be identified by the abbreviation: Cent $Q(k+1) \times Q(k-1)$.

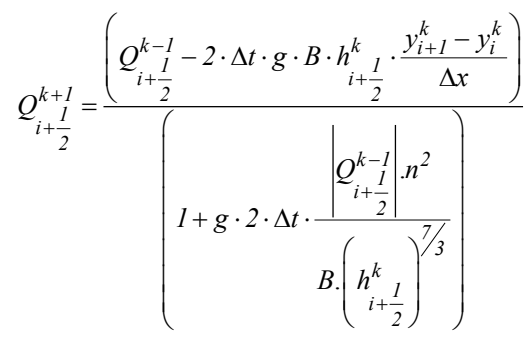

\section{Scheme $Q(k+1) \times Q(k+1)$ :}

In this numerical scheme, the friction term was calculated by the flow at time step $k+1,\left(\left|Q_{i+\frac{1}{2}}^{k+1}\right| Q_{i+\frac{1}{2}}^{k+1}\right.$, Equation 13 shows the scheme for a progressive derivative, identified as $\operatorname{Prog} Q(k+1) \times Q(k+1)$, and Equation 14 for a centered derivative, identified as Cent $Q(k+1) \times Q(k+1)$.

Table 1. Summary of proposed methods and characteristics.

\begin{tabular}{|c|c|c|c|c|}
\hline Method & \multicolumn{4}{|c|}{ Characteristics } \\
\hline Almeida et al. (2012) & Prog & Euler & & $R \approx h$ \\
\hline $\begin{array}{l}\text { Bates, Horritt and } \\
\text { Fewtrell (2010) }\end{array}$ & Prog & Euler & & $R \approx h$ \\
\hline $\begin{array}{l}\text { Bates, Horritt and } \\
\text { Fewtrell (2010) - R }\end{array}$ & Prog & Euler & & $R \approx h B /(2 . h+B)$ \\
\hline Cent $Q(k+1) \times Q(k-1)$ & Cent & Euler & & $R \approx h$ \\
\hline Cent $Q(k+1) \times Q(k-1)-R$ & Cent & Euler & & $R \approx h B /(2 . h+B)$ \\
\hline $\operatorname{Prog} Q(k+1) \times Q(k+1)$ & Prog & Euler & & $R \approx h$ \\
\hline $\operatorname{Prog} Q(k+1) \times Q(k+1)-R$ & Prog & Euler & & $R \approx h B /(2 . h+B)$ \\
\hline Cent $Q(k+1) \times Q(k+1)$ & Cent & Euler & & $R \approx h$ \\
\hline Cent $Q(k+1) \times Q(k+1)-R$ & Cent & Euler & & $R \approx h B /(2 . h+B)$ \\
\hline $\operatorname{Prog} Q(k) \times Q(k)$ & Prog & Euler & & $R \approx h$ \\
\hline $\operatorname{Prog} Q(k) \times Q(k)-R$ & Prog & Euler & & $R \approx h B /(2 . h+B)$ \\
\hline Prog RK2 Q(k)xQ(k) & Prog & $R K 2$ & & $R \approx h$ \\
\hline $\operatorname{Prog} R K 2$ Q (k) $x Q(k)-R$ & Prog & $R K 2$ & $Q_{1}^{k}$ & $R \approx h B /(2 . h+B)$ \\
\hline Prog RK4 Q $(k) \times Q(k)$ & Prog & RK4 & $Q_{{ }_{1+1}}^{k} \mid Q_{j_{1}}^{k}$ & $R \approx h$ \\
\hline $\operatorname{Prog} R K 4$ Q(k)xQ(k) - R & Prog & RK4 & $Q_{1}^{k}{ }_{1} \mid Q_{1}^{k}{ }_{1}$ & $R \approx h B /(2 . h+B)$ \\
\hline
\end{tabular}


$\frac{g \cdot \Delta t \cdot n^{2}}{B .\left(\begin{array}{c}h_{i+\frac{1}{2}}^{k} \\ { }^{7}\end{array}\right)^{7 / 3}} \cdot\left(Q_{i+\frac{1}{2}}^{k+1}\right)^{2}+Q_{i+\frac{1}{2}}^{k+1}+\Delta t \cdot g \cdot B \cdot h_{i+\frac{1}{2}}^{k} \cdot \frac{y_{i+1}^{k}-y_{i}^{k}}{\Delta x}-Q_{i+\frac{1}{2}}^{k}=0$

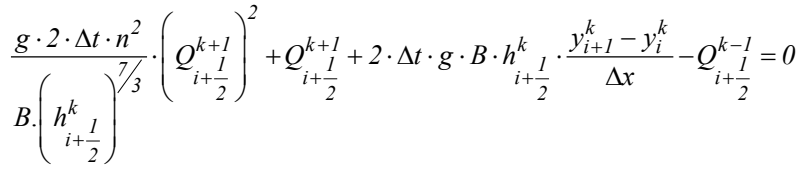

Note that both equations are second-degree polynomial equations: $a x^{2}+b x+c=0$. Therefore, the flow can be calculated directly by the Bhaskara's formula, without the need for an iterative method for resolution. The desired estimate is always the largest root given by: $x_{l}=\frac{-b+\sqrt{b^{2}-4 a c}}{2 a}$. The reasoning is based on the observation that the root $x_{2}\left(\frac{-b-\sqrt{b^{2}-4 a c}}{2 a}\right)$ is always negative,
as shown below.

It is known that the roots sum is given by $x_{1}+x_{2}=-b / a$. Since $b=1$ and $a>0 \quad(g, n, B, h \Delta t$ are always positive), we have $x_{1}+x_{2}<0$. Moreover, since $\frac{\sqrt{b^{2}-4 a c}}{2 a}$ is always positive, so $x_{1}>x_{2}$. Hence $x_{2}<0$, otherwise the sum of the two roots would be positive. Thus, the root $x_{2}$ does not have physical importance as an always negative flow. On the other hand, the root $x_{1}$ can be positive or negative depending on the term c. As $x_{1} \cdot x_{2}=c / a$ and $x_{2}<0$, then the root $x_{1}$ is positive if $c<0$, and negative if $c>0$. In fact, if the flow $Q_{i+\frac{1}{2}}^{k}\left(\right.$ or $\left.Q_{i+\frac{1}{2}}^{k-1}\right)$ is negative, as occurs when the river is subject to the downstream effect, the term $c$ will be positive and the flow at time step $\mathrm{k}+1, Q_{i+\frac{1}{2}}^{k+1}$, is negative.

The scheme is restricted to a new stability condition, in addition to the Courant-Friedrichs-Levy condition, where the discriminant of the Bhaskara's formula must be positive $\left(b^{2}-4 a c>0\right)$ so that the root is not complex. Thus, the condition is given by $a c<1 / 4$. When the flow is positive $\left(x_{1}>0\right)$ it was shown that $a>0$ and $c<0$, satisfying the condition. However, when the flow is negative $\left(x_{1}<0\right)$, the term $c$ is also negative and this condition is mainly dependent on the time step size $(\Delta t)$, the channel stretch size $(\Delta x)$ and the level variation between reaches $\left(y_{i+1}^{k}-y_{i}^{k}\right)$.

\section{Scheme $Q(k)$ x $Q(k)$ :}

Finally, the original numerical scheme was modified by considering the flow at time step $k\left(\left|Q_{i+\frac{1}{2}}^{k}\right| Q_{i+\frac{1}{2}}^{k}\right)$. This scheme allows to calculate the flow directly (Euler) and by the second-and fourth-order Runge-Kutta methods. The flow in time step $k+1$, calculated by the Euler method, is given by Equation 15 and it is identified as $\operatorname{Prog} Q(k) \times Q(k)$.

$$
Q_{i+\frac{1}{2}}^{k+1}=-\frac{g \cdot \Delta t \cdot n^{2}}{B .\left(h_{i+\frac{1}{2}}^{k}\right)^{7 / 3}} \cdot\left|Q_{i+\frac{1}{2}}^{k}\right| \cdot Q_{i+\frac{1}{2}}^{k}-\Delta t \cdot g \cdot B \cdot h_{i+\frac{1}{2}}^{k} \cdot \frac{y_{i+1}^{k}-y_{i}^{k}}{\Delta x}+Q_{i+\frac{1}{2}}^{k}
$$

In the second-order Runge-Kutta method, the flow determined by the Euler method is an intermediate result, where the slope estimate is calculated at the initial point (predictor equation). In the next step, a new estimate is calculated with the predictor result, i.e., the slope estimate is made at the end point. Then, the mean of the two derivatives is calculated to obtain an improved estimate of the slope over the whole range (broker equation). Therefore, Equation 15 is rearranged to define the derivative function $f\left(Q_{i+\frac{1}{2}}^{k}\right)$ (Equation 16), the predictor step is given by Equation 17 (equivalent to Equation 15) and the corrector step by Equation 18. This numerical scheme is identified by the abbreviation Prog RK2 Q(k) $\times Q(k)$.

$$
\begin{aligned}
& f\left(Q_{i+\frac{1}{2}}^{k}\right)=\frac{Q_{i+\frac{1}{2}}^{k+1}-Q_{i+\frac{1}{2}}^{k}}{\Delta t} \\
& f\left(Q_{i+\frac{1}{2}}^{k}\right)=-\frac{g \cdot n^{2}}{B \cdot\left(h_{i+\frac{1}{2}}^{k}\right)^{7 / 3}} \cdot\left|Q_{i+\frac{1}{2}}^{k}\right| \cdot Q_{i+\frac{1}{2}}^{k}-g \cdot B \cdot h_{i+\frac{1}{2}}^{k} \cdot \frac{y_{i+1}^{k}-y_{i}^{k}}{\Delta x}
\end{aligned}
$$

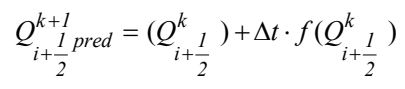

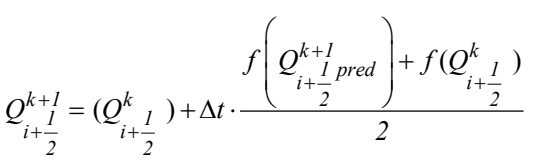

Multiple slope estimates are developed in the fourth-order Runge-Kutta method to obtain an improved mean slope (Equations 19 to 22). Each $K$ value represents a slope and the final equation is a weighted average (Equation 23). This scheme is identified by the abbreviation Prog $R K 4 Q(k) \times Q(k)$. Note that $K_{1}$ is the slope at the interval beginning and $K_{2}$ is the slope at the interval final, equivalent to the second-order Runge-Kutta method.

$$
\begin{aligned}
& K_{1}=f\left(Q_{i+\frac{1}{2}}^{k}\right) \\
& K_{2}=f\left(Q_{i+\frac{1}{2}}^{k}+\frac{1}{2} \cdot K_{l} \cdot \Delta t\right)
\end{aligned}
$$

$K_{3}=f\left(Q_{i+\frac{1}{2}}^{k}+\frac{1}{2} \cdot K_{2} \cdot \Delta t\right)$

$K_{4}=f\left(Q_{i+\frac{1}{2}}^{k}+K_{3} \cdot \Delta t\right)$

$Q_{i+\frac{1}{2}}^{k+1}=Q_{i+\frac{1}{2}}^{k}+\frac{\Delta t}{6} \cdot\left(K_{1}+2 \cdot K_{2}+2 \cdot K_{3}+K_{4}\right)$

\section{EXPERIMENTS}

The described numerical schemes were evaluated in different applications to compare the performance in relation to the same schemes adapted by Fan et al. (2014) of the formulation proposed by Bates, Horritt and Fewtrell (2010) and the formulation 
proposed by Almeida et al. (2012). The schemes were implemented in MATLAB and the simulations were run on eight cores of four Quad-core 3.4 GHz Intel Xeon processors with $8 \mathrm{MB}$ cache memory. The schemes were evaluated for stability (maximum Courant number for which the method remains stable), peak flow at the river's last reach (Qpeak), volume conservation error (VolErr), and the flow's mean square error (RSME), calculated based on the results of simulations performed in the HEC-RAS hydrodynamic model. In addition, each proposed scheme was solved with and without the hydraulic radius simplification, that is, $R \approx h$ and $R=h \cdot B /(2 \cdot h+B)$.

The applications were equivalent to the scenarios tested by Fan et al. (2014). The first test considered a real reach of the São Francisco River, located between Três Marias UHE and the Pirapora city (MG), without lateral contributions. Tests 2, 3 and 4 considered the same reach but with low, high and very high slopes, respectively. In tests 5 and 6 , downstream effects were considered: backwater and tide. The hydrograph input was the same as used by Fan et al. (2014). The simulated period in all tests was 150 hours. Table 2 presents a summary of the data used in the six tests.

\section{RESULTS}

\section{Test 1}

This test considered a real reach of the São Francisco River between the Três Marias UHE and the Pirapora city (MG) with approximate values of $135 \mathrm{~km}$ in length, $300 \mathrm{~m}$ in width (rectangular cross-section), river's slope of $29.5 \mathrm{~cm} / \mathrm{km}$ and Manning's roughness coefficient of 0.030 . The spatial discretization $(\Delta \mathrm{x})$ was $2 \mathrm{~km}$ and time discretization $(\Delta \mathrm{t})$ was varied between 1 and 4 minutes, assuming $C$ values equal to $0.26,0.51,0.77$ and 1.03 at the time of greater depth. A constant slope was considered as a downstream contour condition.
The six formulations of the numerical models described (Equations 12, 13, 14, 15, 18 and 23), the formulation proposed by Bates, Horritt and Fewtrell (2010) (Equation 6) and the formulation proposed by Almeida et al. (2012) with a weighting factor equal to $\theta=0.9$ (Equation 11), adopted based on the authors' results, were tested with and without the hydraulic radius simplification.

All stable schemes presented values similar to the HEC-RAS model since the highest RMSE was $51.48 \mathrm{~m}^{3} \cdot \mathrm{s}^{-1}$ for the Prog $Q(k+1) \times Q(k+1)$ scheme. Figure 1 shows only the region of the hydrograph peak flow in the river's last reach for the original scheme, the Cent $Q(k+1) \times Q(k-1), \operatorname{Prog} Q(k+1) \times Q(k+1), \operatorname{Prog} R K 2$ $Q(k) \times Q(k)$ schemes and the HEC-RAS model, with and without the hydraulic radius simplification. Figure 2 shows the results of the parameters evaluated by varying the time step. In the first column, the results correspond to simulations with the hydraulic radius simplification, and in the second column without. All values are shown in Table A1 of Appendix A.

The Prog $Q(k+1) \times Q(k+1)$ and $\operatorname{Prog} R K 2 Q(k) \times Q(k)$ schemes were the most stable, without instability until $C=1.03$. However, in comparison to the Bates, Horritt and Fewtrell (2010) model, the processing time was on average $33 \%$ higher for the Prog $Q(k+1) \times Q(k+1)$ scheme and twice for the Prog RK2 Q (k) $\times Q(k)$ scheme.

The hydraulic radius calculation without simplification did not increase the processing time of the schemes and their use reduced RMSE. As an example, the scheme of Bates, Horritt and Fewtrell (2010) presented a 60\% lower RMSE when the hydraulic radius was calculated. Despite this, the volume conservation error increased from $0 \%$ to $0.05 \%$, but still remained negligible. This parameter (ErrVol) did not vary with the time step nor with the numerical scheme. It was also observed that the calculation of hydraulic radius did not influence the numerical schemes' stability.

The Almeida et al. (2012) scheme presented no advantages compared to the Bates, Horritt and Fewtrell (2010) scheme in terms of stability (see Table A1 of Appendix A). These schemes were unstable with a time step of $3 \mathrm{~min}(C=0.77)$. All schemes with centered derivative presented instability, with stable results

Table 2. Summary of the parameters used in tests.

\begin{tabular}{|c|c|c|c|}
\hline & $\begin{array}{c}\text { Test } 1 \\
\text { Real reach }\end{array}$ & $\begin{array}{c}\text { Test } 2 \\
\text { Low slope }\end{array}$ & $\begin{array}{c}\text { Test } 3 \\
\text { High slope }\end{array}$ \\
\hline Length & $135 \mathrm{~km}$ & $135 \mathrm{~km}$ & $135 \mathrm{~km}$ \\
\hline Width & $300 \mathrm{~m}$ & $300 \mathrm{~m}$ & $300 \mathrm{~m}$ \\
\hline Declivity & $29.5 \mathrm{~cm} / \mathrm{km}$ & $5 \mathrm{~cm} / \mathrm{km}$ & $300 \mathrm{~cm} / \mathrm{km}$ \\
\hline Initial flow velocity ${ }^{*}$ & $0.89 \mathrm{~m} / \mathrm{s}$ & $0.52 \mathrm{~m} / \mathrm{s}$ & $1.76 \mathrm{~m} / \mathrm{s}$ \\
\hline Manning coef. & 0.03 & 0.03 & 0.03 \\
\hline$\Delta x$ & $2 \mathrm{~km}$ & $2 \mathrm{~km}$ & $2 \mathrm{~km}$ \\
\hline$\Delta t$ & $1,2,3$ and $4 \mathrm{~min}$ & $1,2,3$ and $3,5 \mathrm{~min}$ & $1,2,3$ and $4 \mathrm{~min}$ \\
\hline \multirow[t]{3}{*}{ Downstream effects } & Constant slope & Constant slope & Constant slope \\
\hline & Test 4 & Test 5 & Test 6 \\
\hline & Very high slope & Backwater & Tide \\
\hline Length & $135 \mathrm{~km}$ & $135 \mathrm{~km}$ & $135 \mathrm{~km}$ \\
\hline Width & $300 \mathrm{~m}$ & $300 \mathrm{~m}$ & $300 \mathrm{~m}$ \\
\hline Declivity & $10 \mathrm{~m} / \mathrm{km}$ & $29,5 \mathrm{~cm} / \mathrm{km}$ & $5 \mathrm{~cm} / \mathrm{km}$ \\
\hline Initial flow velocity ${ }^{*}$ & $2.53 \mathrm{~m} / \mathrm{s}$ & $0.89 \mathrm{~m} / \mathrm{s}$ & $0.52 \mathrm{~m} / \mathrm{s}$ \\
\hline Manning coef. & 0.03 & 0.03 & 0.03 \\
\hline$\Delta x$ & $2 \mathrm{~km}$ & $2 \mathrm{~km}$ & $2 \mathrm{~km}$ \\
\hline$\Delta t$ & $80,120,160$ and $200 \mathrm{seg}$ & $80,120,150$ and $180 \mathrm{seg}$ & $1,2,3$ and $4 \mathrm{~min}$ \\
\hline Downstream effects & Constant slope & Backwater & Tide \\
\hline
\end{tabular}

*Flow velocity calculated by the initial flow, width and initial depth (Manning's Eq. with simplification of the hydraulic radius). 
only for the time step of 1 minute $(C=0.26)$. In addition, these schemes did not improve the RMSE and the volume conservation error, as was expected for a second-order approximation scheme with respect to a first-order scheme.

\section{Test 2}

This test considered the same conditions of the river reach used in test 1 but it used a river's low slope of $5 \mathrm{~cm} / \mathrm{km}$. The time step was varied in 1, 2, 3 and 3.5 minutes, corresponding

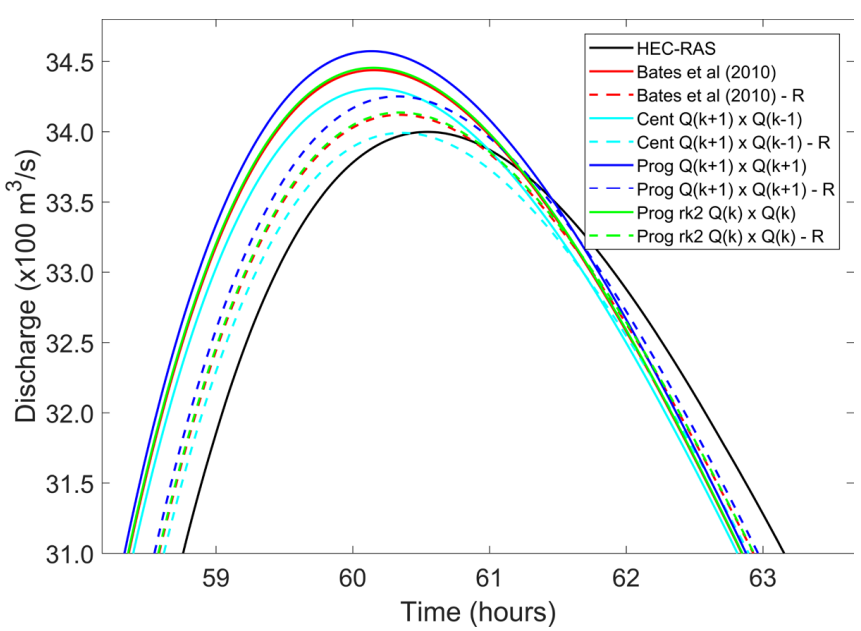

Figure 1. Region of the hydrograph peak flow in the river's last reach for the Bates, Horritt and Fewtrell (2010), Cent $Q(k+1) \times Q(k-1), \operatorname{Prog} Q(k+1) \times Q(k+1)$ and $\operatorname{Prog} R K 2 Q(k) \times Q(k)$ schemes with and without the hydraulic radius simplification considering a river's slope equal to $29.5 \mathrm{~cm} / \mathrm{km}$.

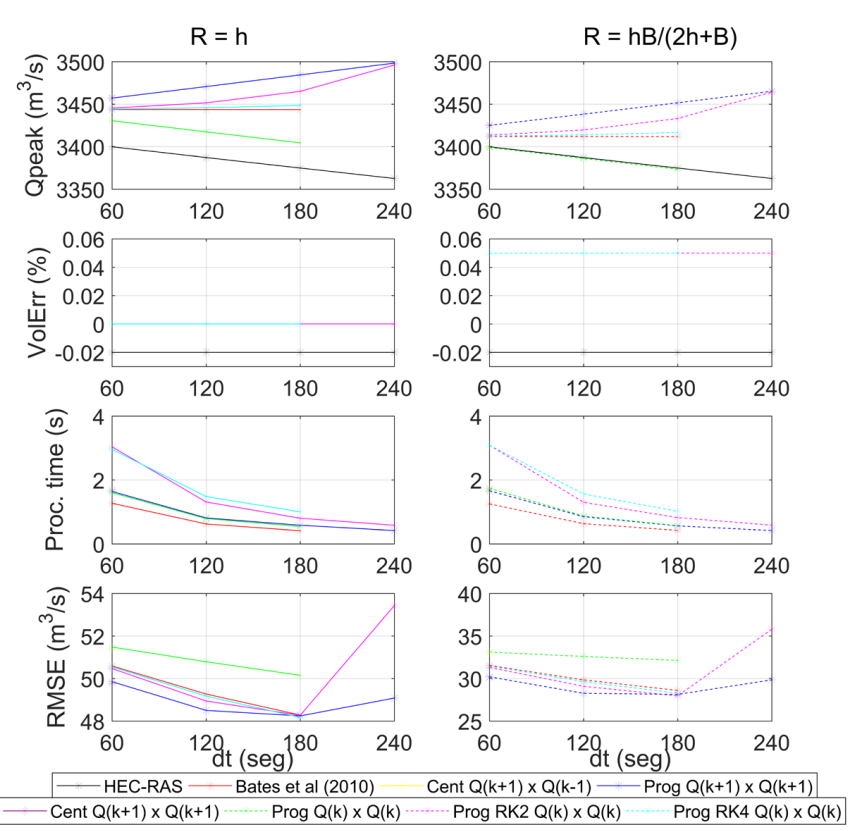

Figure 2. Peak flow, volume conservation error, processing time and RMSE in relation to the time step for different formulations of numerical schemes considering a river's slope equal to $29.5 \mathrm{~cm} / \mathrm{km}$. to $C$ values of $0.29,0.60,1.90$ and 1.04 , respectively, at the time of greater depth. As in test 1 , the numerical schemes' performance was compared. Figure 3 shows the peak flow region in the last reach for the original scheme, the $\operatorname{Prog} Q(k+1) \times Q(k+1)$, $\operatorname{Prog} \mathrm{RK} 2 Q(k) \times Q(k)$ schemes and the HEC-RAS model. Figure 4 shows the performance of all schemes evaluated and Table A2 ( Appendix A) shows the values of Figure 4.

The Prog Q $(k+1) \times Q(k+1)$ scheme was the most stable, with stability up to the time step of $3.5 \mathrm{~min}(C=1.04)$, and with an increase in processing time of $20 \%$ relative to the original scheme. In addition, it was the scheme that presented the highest RMSE values.

Schemes with centered derivative presented instability at all time steps adopted. The other schemes, such as Bates, Horritt and Fewtrell (2010) and Almeida et al. (2012), presented equal stability up to a time step of $3 \min (C=0.90)$.

The Prog $Q(k) \times Q(k)$ scheme presented the lowest RMSE with practically the same processing time as the original model. The Prog RK2 Q(k)xQ(k) and Prog RK4 Q(k)xQ(k) schemes presented RMSE values closer to the ones in Bates, Horritt and Fewtrell (2010), but the processing time was, on average, almost twice.

The volume conservation error did not changed with the time step but increased from $0.57 \%$ to $0.75 \%$ when the calculation of the hydraulic radius was included in the numerical scheme. This inclusion of this calculation did not increase the processing time, as observed in Figure 4, and led to the results closer to that of the HEC-RAS model, reducing RMSE by $64 \%$ compared to the Bates, Horritt and Fewtrell (2010) scheme.

\section{Test 3}

In this test, a high slope of $300 \mathrm{~cm} / \mathrm{km}$ was considered. The time step was varied between 1 and 4 minutes corresponding to $C$ values of $0.18,0.37,0.55,0.74$ at the time of greatest depth. Figure 5 shows a section of the hydrograph at the river's last reach for the original scheme, the Cent $Q(k+1) \times Q(k-1), \operatorname{Prog} Q(k+1) \times Q(k+1)$

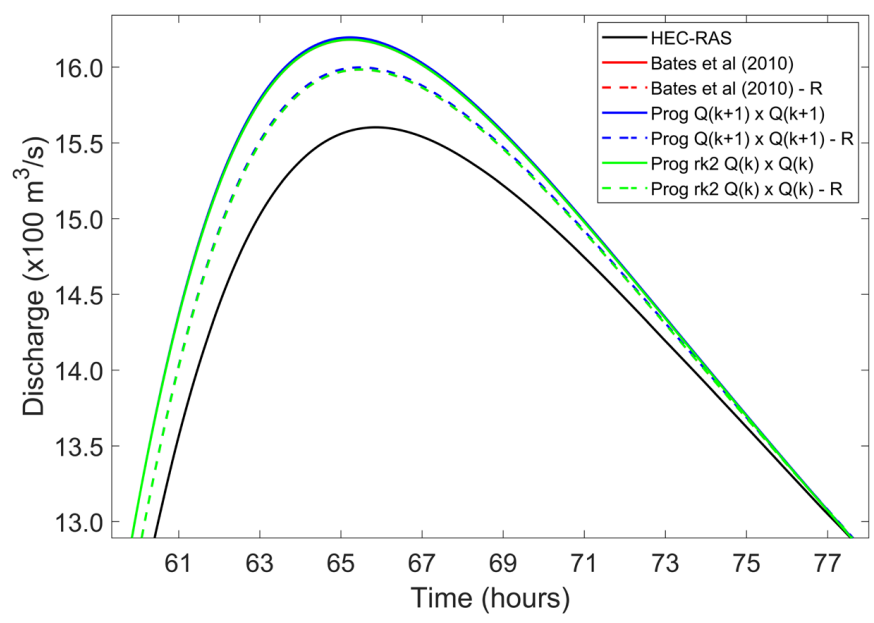

Figure 3. Region of the hydrograph peak flow in the river's last reach for the Bates, Horritt and Fewtrell (2010), ProgQ $(k+1) x Q(k+1)$ and Prog RK2 Q(k)xQ(k) schemes with and without the hydraulic radius simplification considering a river's slope equal to $5 \mathrm{~cm} / \mathrm{km}$ (the red line is subscribed by the green line). 

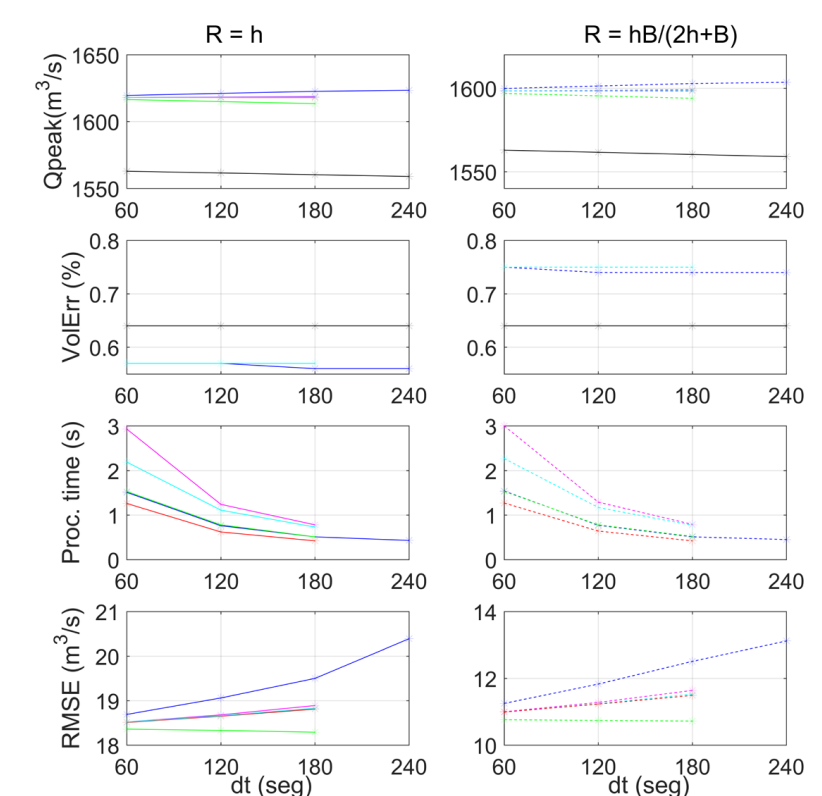

\begin{tabular}{|llll|}
\hline - HEC-RAS - Bates et al $(2010)$ & Cent $Q(k+1) \times Q(k-1)$ & Prog $Q(k+1) \times Q(k+1)$ \\
\hline Cent $Q(k+1) \times Q(k+1)$ & Prog $Q(k) \times Q(k)$ & Prog RK2 $Q(k) \times Q(k)$ & Prog RK4 $Q(k) \times Q(k)$ \\
\hline
\end{tabular}

Figure 4. Peak flow, volume conservation error, processing time and RMSE in relation to the time step for different formulations of numerical schemes considering a river's slope equal to $5 \mathrm{~cm} / \mathrm{km}$.

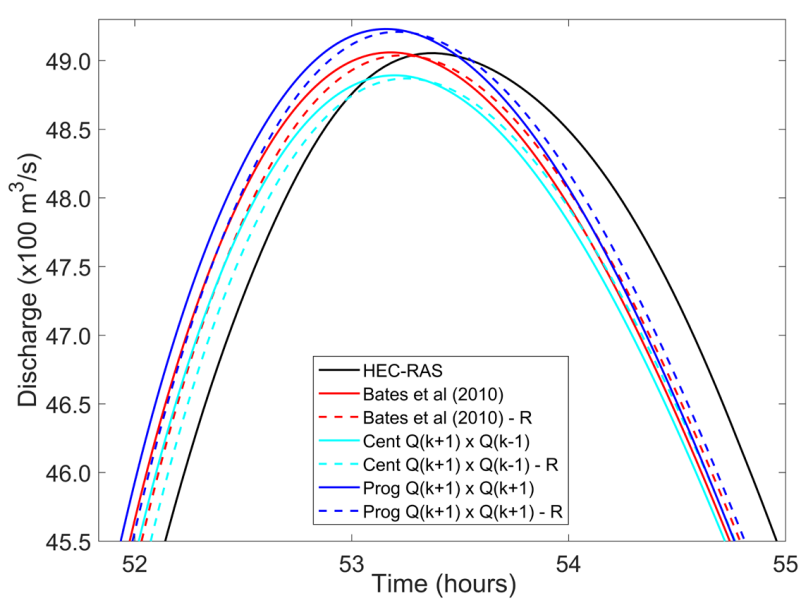

Figure 5. Region of the hydrograph peak flow in the river's last reach for the Bates, Horritt and Fewtrell (2010), Cent Q(k+1)xQ(k-1) and $\operatorname{Prog} Q(k+1) \times Q(k+1)$ schemes with and without the hydraulic radius simplification considering a river's slope equal to $300 \mathrm{~cm} / \mathrm{km}$.

schemes and HEC-RAS. Figures 6 shows the main results and Table A3 (Appendix A) the detailed results.

As in the previous tests, the $\operatorname{Prog} Q(k+1) \times Q(k+1)$ scheme was the most stable, reaching the value of $C$ equal to 0.74 compared to 0.37 in the Bates, Horritt and Fewtrell (2010) and Almeida et al. (2012) schemes. The increase in processing time compared to the original scheme was $20 \%$.

The Cent $Q(k+1) \times Q(k+1)$ scheme also presented better performance than the original model, with stability up to the
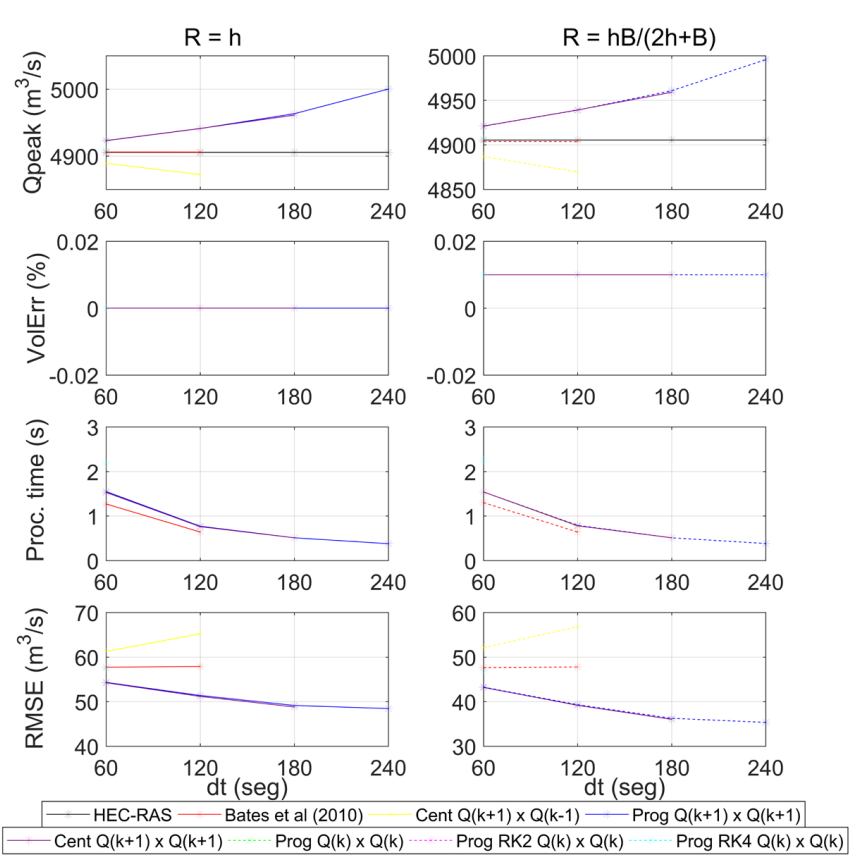

Figure 6. Peak flow, volume conservation error, processing time and RMSE in relation to the time step for different formulations of numerical schemes considering a river's slope equal to $300 \mathrm{~cm} / \mathrm{km}$.

time step of 3 minutes $(C=0.55)$. However, the Prog $Q(k) \times Q(k)$, Prog RK2 Q(k)xQ(k) and Prog RK4 Q(k)xQ(k) schemes did not show any improvement over the original scheme.

The inclusion of the hydraulic radius calculation in numerical schemes reduced the RMSE by $20 \%$ in the original scheme and by $30 \%$ in the $\operatorname{Prog} Q(k+1) \times Q(k+1)$ scheme. Moreover, the increase in the volume conservation error from 0 to $0.01 \%$ is negligible considering this calculation.

\section{Test 4}

The same river's reach of test 1 with a very high slope of $10 \mathrm{~m} / \mathrm{km}$ was considered in this test. This slope changes the flow regime to the supercritical regime, where the original inertial model does not show good stability results (FAN et al., 2014). The time step was varied with values of 80, 120, 160 and 200 seconds, corresponding to the values of $\mathrm{C}$ at the time of greatest depth of $0.20,0.31,0.41$, and 0.51 , respectively. Figures 7 and 8 present the main results and Table A4 (Appendix A) the detailed results.

Only the numerical schemes $\operatorname{Prog} Q(k+1) x Q(k+1)$, Cent $Q(k+1) \times Q(k+1)$, Bates, Horritt and Fewtrell (2010) and Almeida et al. (2012) presented stable results. The last two were stable only in the time step adopted in the simulation of $80 \mathrm{sec}$, corresponding to $C=0.20$. The other two schemes were stable up to $160 \mathrm{sec}(C=0.41)$. Despite the improvement, where the Courant number increased from 0.20 to 0.41 , the value is still small compared to other models of flood propagation where $C$ can reach 1.

The $\operatorname{Prog} Q(k+1) \times Q(k+1)$ and $\operatorname{Cent} Q(k+1) \times Q(k+1)$ schemes showed practically identical performances with near peak flow, volume 
conservation error, processing time and RMSE. In addition, the processing time of these schemes was the same as the original scheme with a slightly higher RMSE, $31.24 \mathrm{~m}^{3} / \mathrm{s}$ compared to $30.19 \mathrm{~m}^{3} / \mathrm{s}$.

As in the other tests, the inclusion of the hydraulic radius calculation in the numerical schemes did not increase the processing time, reduced the RMSE from 30.19 to 25.75 in the model of Bates, Horritt and Fewtrell (2010) while the volume conservation error increased from 0 to $0.01 \%$ in all stable numerical schemes, but may be considered negligible.

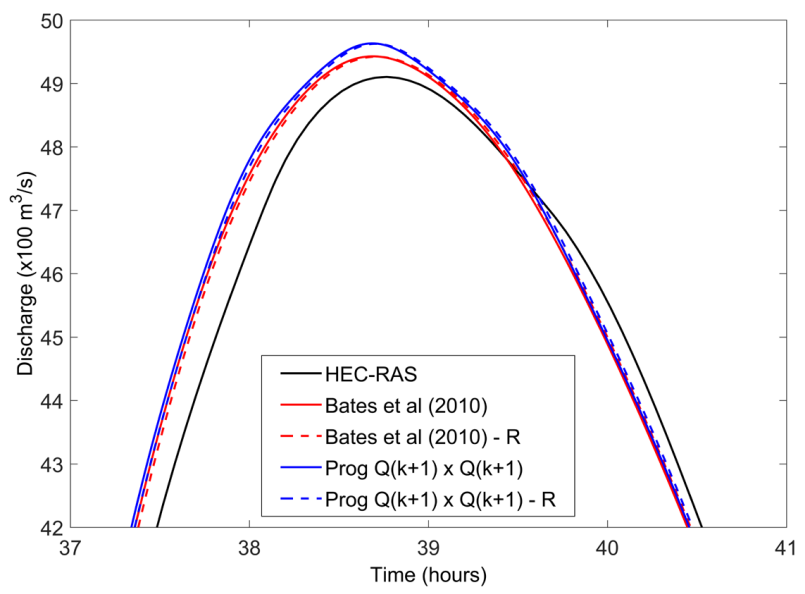

Figure 7. Region of the hydrograph peak flow in the river's last reach for the Bates, Horritt and Fewtrell (2010) and Prog $Q(k+1) \times Q(k+1)$ schemes with and without the hydraulic radius simplification considering a river's slope equal to $10 \mathrm{~cm} / \mathrm{km}$.
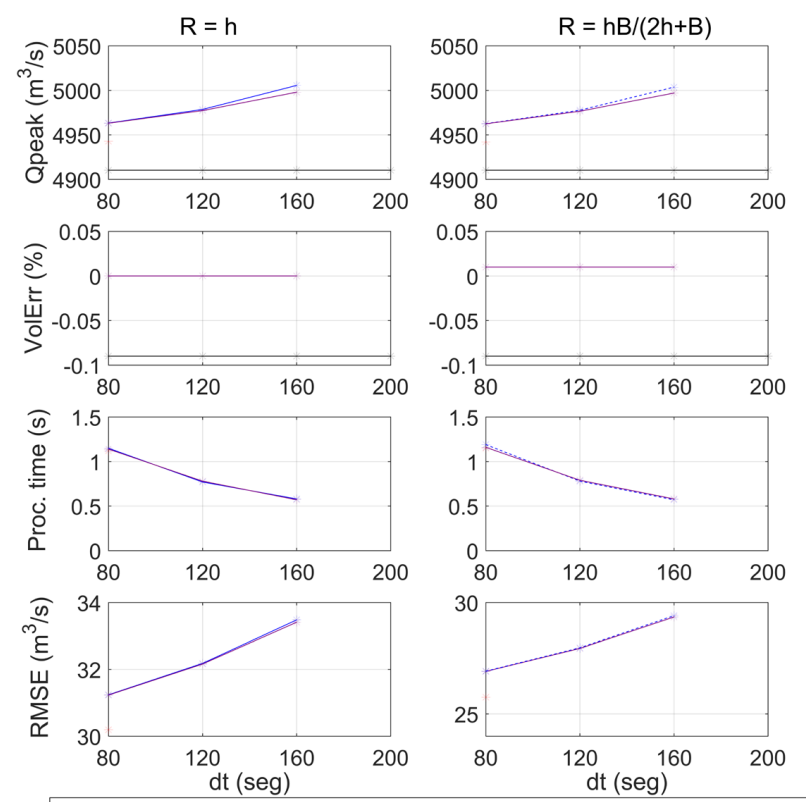

- HEC-RAS - Bates et al (2010) Cent $Q(k+1) \times Q(k-1)-\operatorname{Prog} Q(k+1) \times Q(k+1)$

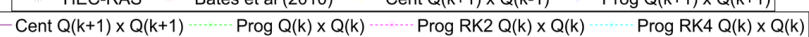

Figure 8. Peak flow, volume conservation error, processing time and RMSE in relation to the time step for different formulations of numerical schemes considering a river's slope equal to $10 \mathrm{~m} / \mathrm{km}$.

\section{Test 5}

This application was identical to test 1 but considered a constant water level downstream and a constant initial level from the half of the reach as boundary conditions. These conditions represent a dam operating at constant water level in simplified form. Other models of flood propagation, such as MuskingumCunge, are invalidated in the presence of dam and backwater (FAN et al., 2014). The time step was varied with values of 1 , 2, 2.2 and 2.5 minutes, corresponding to the maximum $C$ values of $0.44,0.88,0.97$ and $>1$ at the moment of greatest depth (higher values computed during the simulation). Figure 9 shows a hydrograph of the last reach for the original, $\operatorname{Prog} Q(k+1) \times Q(k+1)$ and Prog RK2 Q(k)xQ(k) schemes. Figure 10 shows the main results and Table A5 (Appendix A) the detailed results.

All numerical schemes, with the exception of the centered derivative schemes, showed stable results until the adopted time step of $132 \mathrm{sec}(\mathrm{C}=0.97)$. The processing times of the $\operatorname{Prog} Q(k+1) \times Q(k+1)$ and $\operatorname{Prog} Q(k) \times Q(k)$ schemes presented an average increase of $25 \%$ in comparison to the original scheme. On the other hand, the Prog RK2 Q(k) xQ(k) and Prog RK4 Q(k)xQ(k) schemes took twice as long as the original scheme.

In this application, the volume conservation error did not change with the inclusion of the hydraulic radius calculation. In addition, the peak flow approached the HEC-RAS model's peak flow and the RMSE decreases.

\section{Test 6}

In this test, we considered a situation equal to test 2 , low slope, but with different contour conditions. A constant flow of $500 \mathrm{~m}^{3} / \mathrm{s}$ was adopted as the upstream condition and a variable

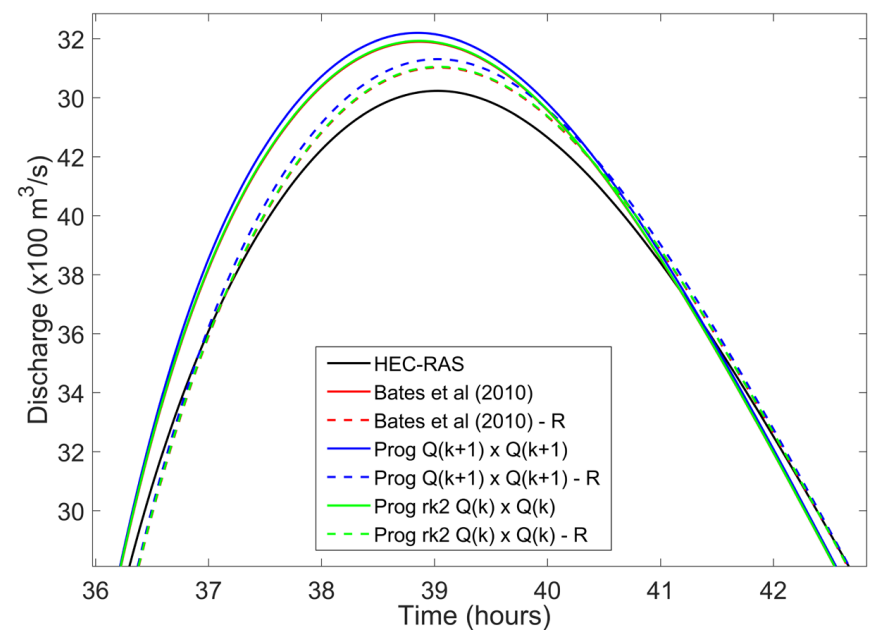

Figure 9. Region of the hydrograph peak flow in the river's last reach for the Bates, Horritt and Fewtrell (2010), $\operatorname{Prog} Q(k+1) x Q(k+1)$ and Prog $R K 2 Q(k) \times Q(k)$ schemes with and without the hydraulic radius simplification considering a boundary condition downstream of dam and backwater (the red line is subscribed by the green line). 


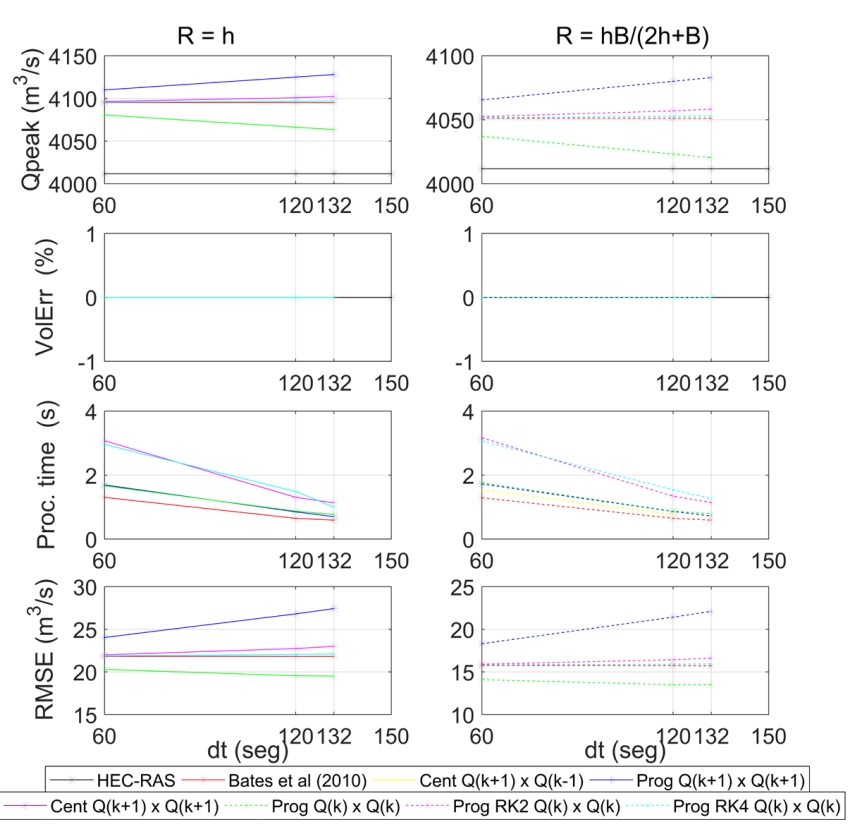

Figure 10. Peak flow, volume conservation error, processing time and RMSE in relation to the time step for different formulations of numerical schemes considering a boundary condition downstream of dam and backwater.

level as the downstream condition. The water level downstream (y) was given by the equation $y=6+2 \operatorname{sen}\left(\frac{T \pi}{6}\right)$, which represents a periodic level variation between $4 \mathrm{~m}$ and $8 \mathrm{~m}$ with a period of 12 hours. This downstream condition - tidal variation - causes a wave that propagates upstream and which can reverse the flow direction in the river's last reach during some moments along the tide cycle.

The time step was varied between 1,2,3.5 and 4 minutes with maximum values of $C$ equal to $0.27,0.54,0.94$ and 1.07 (highest values computed during the simulation), respectively. Figure 11 shows a region of the hydrograph peak in the last reach for the original scheme and for the Prog $R K 2 Q(k) \times Q(k)$ scheme. Figure 12 shows the main results and Table A6 (Appendix A) the detailed results.

Unlike the other applications, in this test the ProgQ $(k+1) \times Q(k+1)$ scheme was not stable in any adopted time step. As shown, the scheme requires that the discriminant of the Bhaskara's formula be positive and this criterion was not fulfilled even with a very small time step.

The most stable scheme was Prog $R K 2 Q(k) \times Q(k)$ with $C$ equal to 1.07 (time step of 4 minutes), followed by the other schemes, with $C=0.94$ (3.5 min). Despite the improvement in stability, the Prog RK2 Q(k)xQ(k) scheme took, on average, twice the original scheme time and presented higher RMSE.

The volume conservation error and RMSE were equal in all stable schemes, approximately $0.97 \%$, and had a slight increase when the calculation of the hydraulic radius was considered.

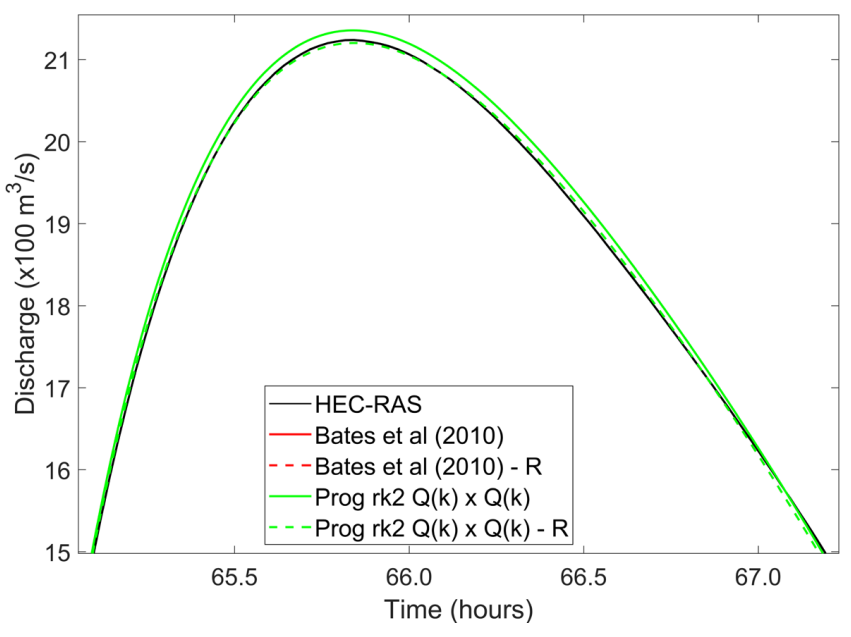

Figure 11. Region of the hydrograph peak flow in the river's last reach for the Bates, Horritt and Fewtrell (2010) and Prog RK2 Q(k)xQ(k) schemes with and without the hydraulic radius simplification considering a boundary condition with tide variation (the red line is subscribed by the green line).
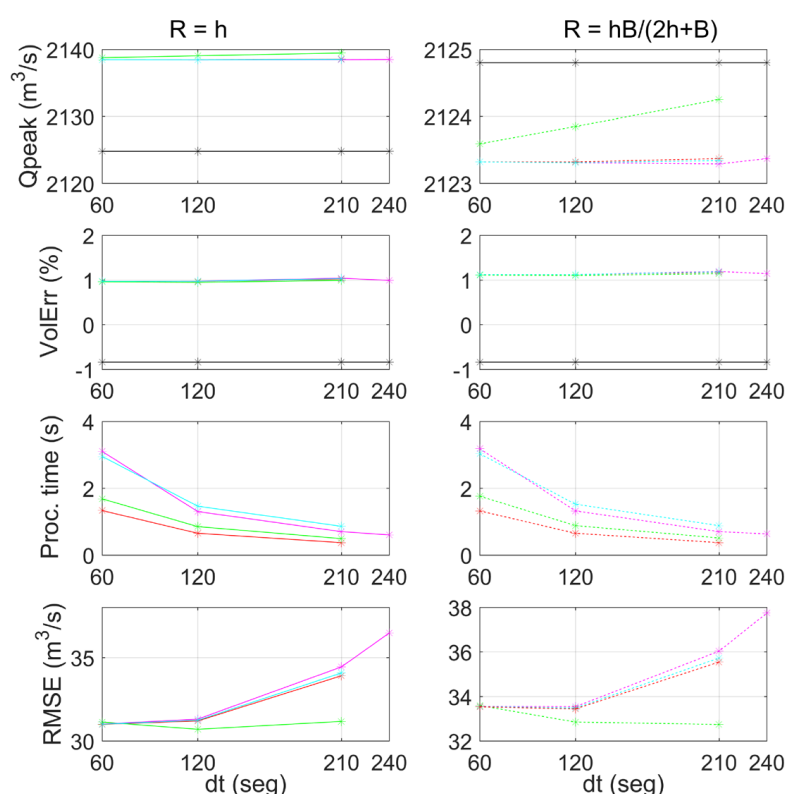

* - HEC-RAS — Bates et al (2010) Cent $\mathrm{Q}(\mathrm{k}+1) \times \mathrm{Q}(\mathrm{k}-1) \rightleftharpoons$ Prog $\mathrm{Q}(\mathrm{k}+1) \times \mathrm{Q}(\mathrm{k}+1)$ * Cent $Q(k+1) \times Q(k+1) \cdots \operatorname{Prog} Q(k) \times Q(k) \cdots$ Prog RK2 $Q(k) \times Q(k) \quad$ Prog RK4 $Q(k) \times Q(k)$

Figure 12. Peak flow, volume conservation error, processing time and RMSE in relation to the time step for different formulations of numerical schemes considering a boundary condition with tide variation.

\section{CONCLUSIONS}

This paper compared the performance of new numerical schemes with inertial approximation of the Saint-Venant equations. The differences between the numerical schemes in terms of 
stability, peak flow, volume conservation error and RMSE were investigated. All stable schemes presented similar results to the hydrodynamic model HEC-RAS, and can be used with good accuracy in comparion to the model that considers the complete equations of Sant-Venant. The advantages of the proposed schemes are ease of implementation, robustness in the coupling with hydrodynamic models and the possibility of parallelization. However, more comparison of the inertial model with implicit and explicit numerical schemes is recommended for future studies.

With respect to performance measures, Table 3 presents the best scheme(s) in each metric and in each test. The difference of the peak flow and the volume conservation error between schemes can be considered negligible. Furthermore, although the original scheme is faster, the difference in processing time is very small in relation to the $\operatorname{Prog} Q(k) \times Q(k)$ and the $\operatorname{Prog} Q(k+1) \times Q(k+1)$ schemes.

It was observed for all stable numerical schemes that the peak flow approaches the HEC-RAS model's peak flow and that the RMSE decreases when the hydraulic radius calculation is considered without simplification. In this way, the inertial model formulation is more similar to what is done in the HEC-RAS, which does not simplify the hydraulic radius calculation. In addition, the processing time did not increase with this calculation and the volume conservation error showed a negligible increase.

In general, the scheme proposed by Almeida et al. (2012) presented no advantages in relation to the Bates, Horritt and Fewtrell (2010) scheme. In all tests, both models presented instability at the same time step and both RMSE and peak flow were equivalent. The processing time was equal or greater in the Almeida et al. (2012) scheme.

Schemes with centered numerical derivatives showed instability for low $C$ values in tests 1, 2, 5 and 6. Only in the applications of test 3 (high slope) and test 4 (very high slope) the Cent $Q(k+1) \times Q(k+1)$ scheme showed an advantage over the others. On the other hand, the second order approximation scheme,
Prog RK2 Q(k)xQ(k), did not show stability in these tests (3 and 4). For this scheme, the stability was equivalent to original model in tests 2 and 5 and greater in tests 1 and 6 . The disadvantage of the schemes with second and fourth order approximations is the longer processing time.

The parabola scheme, whose solution is a second degree equation $(\operatorname{Prog} Q(k+1) x Q(k+1))$, presented advantages in relation to the Bates, Horritt and Fewtrell (2010) scheme in most applications. In tests 1, 2, 3 and 4 the proposed model was the most stable, presenting good results with $C$ values of $1.03,1.04,0.74$ and 0.41 , respectively, compared to the maximum values of $0.77,0.90,0.37$ and 0.20 for the original scheme. In test 5 (dam and backwater), the stability was equal in both schemes $(C=0.97)$. However, in test 6 (tide), the parabola scheme was not stable at any time step. The proposed scheme is more unstable in negative flow situations.

The parabola scheme's processing time was equal to or slightly higher than the original model. This difference is in the tenths of a second scale and may be considered negligible. Moreover, in applications that do not occur negative flow, the greater stability makes this scheme faster because it allows to adopt a greater time step. As an example, in the supercritical regime application (test 4 ) the proposed scheme spent $0.58 \mathrm{sec}$ (time step $160 \mathrm{sec}$ ) and the original scheme spent $1.12 \mathrm{sec}$ (time step $80 \mathrm{sec}$ ). Regarding RMSE, despite the higher values in the parabola scheme in tests 2 (low slope) and 5 (dam and backwater), the difference with the original model is very small. The largest difference found was $2.3 \mathrm{~m}^{3} / \mathrm{s}$ (RMSE of $22.52 \mathrm{~m}^{3} / \mathrm{s}$ compared to $24.82 \mathrm{~m}^{3} / \mathrm{s}$ ) in test 5 .

Therefore, among all tests performed, we believe that the important information raised in the research is that the greater stability of the parabola scheme makes this scheme more attractive than the original model for use as flow propagation modulus in hydrological models. However this use is limited

Table 3. The best numerical scheme(s) in each test in relation to metrics.

\begin{tabular}{|c|c|c|c|}
\hline & $\begin{array}{c}\text { Test } 1 \\
\text { Real reach } \\
\end{array}$ & $\begin{array}{c}\text { Test } 2 \\
\text { Low slope }\end{array}$ & $\begin{array}{c}\text { Test } 3 \\
\text { High slope }\end{array}$ \\
\hline$C^{*}$ & $\begin{array}{c}\operatorname{Prog} Q(k+1) \times Q(k+1) \\
\text { and } \operatorname{Prog} R K 2 Q(k) \times Q(k)\end{array}$ & $\operatorname{Prog} Q(k+1) \times Q(k+1)$ & $\operatorname{Prog} Q(k+1) \times Q(k+1)$ \\
\hline Qpeak & Negligible & Negligible & Negligible \\
\hline VolErr & Negligible & Negligible & Negligible \\
\hline Processing Time & Bates, Horritt and Fewtrell $(2010)^{* *}$ & Bates, Horritt and Fewtrell $(2010)^{* *}$ & Bates, Horritt and Fewtrell (2010) ${ }^{* *}$ \\
\hline \multirow[t]{3}{*}{ RSME } & $\operatorname{Prog} Q(k+1) \times Q(k+1)$ & $\operatorname{Prog} Q(k) \times Q(k)$ & $\begin{array}{c}\operatorname{Prog} Q(k+1) \times Q(k+1) \\
\text { and Cent } Q(k+1) \times Q(k+1)\end{array}$ \\
\hline & Test 4 & Test 5 & Test 6 \\
\hline & Very high slope & Backwater & Tide \\
\hline$C^{*}$ & $\begin{array}{c}\operatorname{Prog} Q(k+1) \times Q(k+1) \\
\text { and Cent } Q(k+1) \times Q(k+1)\end{array}$ & $* * *$ & $\operatorname{Prog} R K 2 Q(k) \times Q(k)$ \\
\hline Qpeak & Negligible & Negligible & Negligible \\
\hline VolErr & Negligible & Negligible & Negligible \\
\hline $\begin{array}{l}\text { Processing } \\
\text { Time }\end{array}$ & Negligible & Bates, Horritt and Fewtrell $(2010)^{* *}$ & Bates, Horritt and Fewtrell $(2010)^{* *}$ \\
\hline RSME & Negligible & $\operatorname{Prog} Q(k) \times Q(k)$ & $\operatorname{Prog} Q(k) \times Q(k)$ \\
\hline
\end{tabular}

*Maximum Courant number for which the method remains stable; **Difference is very small in relation to $\operatorname{Prog} Q(k) x Q(k)$ and $\operatorname{Prog} Q(k+1) x Q(k+1) ; * * *$ Same for all schemes, with exception of schemes with centered derivative. 
in some cases where there are negative flows, which reduces one of the main applications of models using the inertial model. This disadvantage could easily be overcome by using an adaptive mixed method which recognizes the possibility of a flow reversal and adapts temporarily to another scheme and then returns to the parabola scheme as soon as the negative flow disappears.

Finally, it is important to emphasize that, according to the results, the inclusion of the hydraulic radius calculation without simplification in the numerical schemes improved the results without increasing the computational time. That is, the inclusion of this consideration approximates the results of physical reality without additional performance costs.

\section{ACKNOWLEDGEMENTS}

The authors would like to thank CNPq for the doctoral fellowship granted to the first author and anonymous reviewers for useful comments on the final draft.

\section{REFERENCES}

ALMEIDA, G. A. M.; BATES, P. Applicability of the local inertial approximation of the shallow water equations to flood modeling. Water Resources Research, v. 49, n. 8, p. 4833-4844, 2013. http:// dx.doi.org/10.1002/wrcr.20366.

ALMEIDA, G. A. M.; BATES, P.; FREER, J. E.; SOUVIGNET, M. Improving the stability of a simple formulation of the shallow water equations for 2-D flood modeling. Water Resources Research, v. 48, n. 5, p. W05528, 2012. http://dx.doi.org/10.1029/2011WR011570.

BATES, P. D.; HORRITT, M. S.; FEWTRELL, T. J. A simple inertial formulation of the shallow water equations for efficient two-dimensional flood inundation modelling. Journal of Hydrology, v. 387, n. 1, p. 33-45, 2010. http://dx.doi.org/10.1016/j. jhydrol.2010.03.027.

BEVEN, K. J. Rainfall-runoff modelling: the primer. New Jersey: John Wiley \& Sons, 2011.

CHANSON, H. The bydraulics of open channel flow: an introduction. 2nd ed. Oxford: Butterworth-Heinemann, 2004. 630 p.

CHAPRA, S. C.; CANALE, R. P. Numerical methods for engineers. New York: McGraw-Hill, 2012.

COULTHARD, T. J.; NEAL, J. C.; BATES, P. D.; RAMIREZ, J.; ALMEIDA, G. A. M.; HANCOCK, G. R. Integrating the LISFLOOD-FP 2D hydrodynamic model with the CAESAR model: implications for modelling landscape evolution. Earth Surface Processes and Landforms, v. 38, n. 15, p. 1897-1906, 2013. http://dx.doi.org/10.1002/esp.3478.

CUNGE, J. A. On the subject of a flood propagation computation method (Muskingum method). Journal of Hydrology Research, v. 7, n. 2, p. 205-230, 1969. http://dx.doi.org/10.1080/00221686909500264.
CUNGE, J. A.; HOLLY, F. M.; VERWEY, A. Practical aspects of computational river hydraulics. Boston: Pitman, 1980.420 p.

DOTTORI, F.; TODINI, E. Developments of a flood inundation model based on the cellular automata approach: testing different methods to improve model performance. Physics and Chemistry of the Earth Parts A/B/C, v. 36, n. 7, p. 266-280, 2011. http://dx.doi. org/10.1016/j.pce.2011.02.004.

FAN, F. M.; PONTES, P. R. M.; PAIVA, R. C. D.; COLLISCHONN, W. Avaliação de um método de propagação de cheias em rios com aproximação inercial das equações de Saint-Venant. Revista Brasileira de Recursos Hídricos, v. 19, n. 4, p. 137-147, 2014. http:/ / dx.doi.org/10.21168/rbrh.v19n4.p137-147.

FREAD, D. L. Flow routing in handbook of hydrology. In: MAIDMENT, D. R. (Ed.). Handbook of hydrology. New York: McGraw-Hill Inc., 1993. p. 10.1-10.36.

MONTEIRO, L. R.; FAN, F. M.; COLLISCHONN, W.; SCHETTINI, E. B. C. Simulação da onda superficial provocada pelo fechamento de comportas utilizando uma aproximação inercial da Equação de Saint-Venant/ Surface waves caused by gates closure simulation with an inertial approximation of Saint-Venant Equation. Revista Brasileira de Recursos Hídricos, v. 20, n. 4, p. 927-936, 2015. http:/ / dx.doi.org/10.21168/rbrh.v20n4.p927-936.

MONTERO, R. A.; SCHWANENBERG, D.; HATZ, M.; BRINKMANN, M. Simplified hydraulic modelling in model predictive control of flood mitigation measures along rivers. Journal of Applied Water Engineering and Research, v. 1, n. 1, p. 17-27, 2013. http://dx.doi.org/10.1080/23249676.2013.827897.

NEAL, J. C.; SCHUMANN, G. J.-P.; FEWTRELL, T. J.; BUDIMIR, M.; BATES, P. D.; MASON, D. Evaluating a new LISFLOOD-FP formulation using data for the summer 2007 floods in Tewkesbury, UK. Journal of Flood Risk Management, v. 4, n. 2, p. 88-95, 2011. http://dx.doi.org/10.1111/j.1753-318X.2011.01093.x.

NEAL, J.; SCHUMANN, G.; BATES, P. A subgrid channel model for simulating river hydraulics and floodplain inundation over large and data sparse areas. Water Resources Research, v. 48, n. 11, 2012. http://dx.doi.org/10.1029/2012WR012514.

NÉELZ, S.; PENDER, G. (2009). Desktop review of 2D bydraulic modelling packages. Bristol: Defra/Environment Agency. Science Report SC080035.

PONCE, V. M. Engineering hydrology, principles and practices. New Jersey: Prentice Hall, 1989. 640 p.

PONTES, P. R. M.; COLLISCHONN, W.; FAN, F.M.; PAIVA, R.C.D.; BUARQUE, D.C. Modelagem hidrológica e hidráulica de grande escala com propagação inercial de vazões. Revista Brasileira de Recursos Hídricos, vol. 20, n. 4, p. 888-904, 2015. http://dx.doi. org/10.21168/rbrh.v20n4.p888-904. 
PONTES, P. R. M.; FAN, F. M.; FLEISCHMANN, A. S.; PAIVA, R. C. D.; BUARQUE, D. C.; SIQUEIRA, V. A.; JARDIM, P. F.; SORRIBAS, M. V.; COLLISCHONN, W. MGB-IPH model for hydrological and hydraulic simulation of large floodplain river systems coupled with open source GIS. Environmental Modelling \& Software, v. 94, p. 1-20, 2017. http://dx.doi.org/10.1016/j. envsoft.2017.03.029.

POPESCU, I. Computational bydraulics. London: IWA Publishing, 2014.

SAMPSON, C. C.; SMITH, A. M.; BATES, P. D.; NEAL, J. C.; ALFIERI, L.; FREER, J. E. A high-resolution global flood hazard model. Water Resources Research, v. 51, n. 9, p. 7358-7381, 2015. PMid:27594719. http://dx.doi.org/10.1002/2015WR016954.

TUCCI, C. E. M. Modelos hidrológicos. 2. ed. Porto Alegre: Editora da UFRGS, 2005.

US ARMY CORPS OF ENGINEERS - USACE. HEC-RAS River Analysis System Hydraulic Reference Manual. Version 5.0. Davis: Hydrologic Engineering Center, 2016.

YAMAZAKI, D.; ALMEIDA, G. A. M.; BATES, P. D. Improving computational efficiency in global river models by implementing the local inertial flow equation and a vector-based river network map. Water Resources Research, v. 49, n. 11, p. 7221-7235, 2013.

YEN, B. C.; TSAI, C. W.-S. Noninertial wave vs. diffusion wave in flood routing. Journal of Hydrology, v. 244, n. 1-2, p. 97-104, 2001. http://dx.doi.org/10.1016/S0022-1694(00)00422-4.

\section{Authors contributions}

Alice César Fassoni-Andrade: General design, data processing and analysis, discussion of the results and writing.

Fernando Mainardi Fan: General design, discussion of the results, writing and review.

Walter Collischonn: General design, discussion of the results and review.

Artur César Fassoni: Numerical schemes design, discussion of the results and review.

Rodrigo Cauduro Dias de Paiva: Discussion of the results and review. 

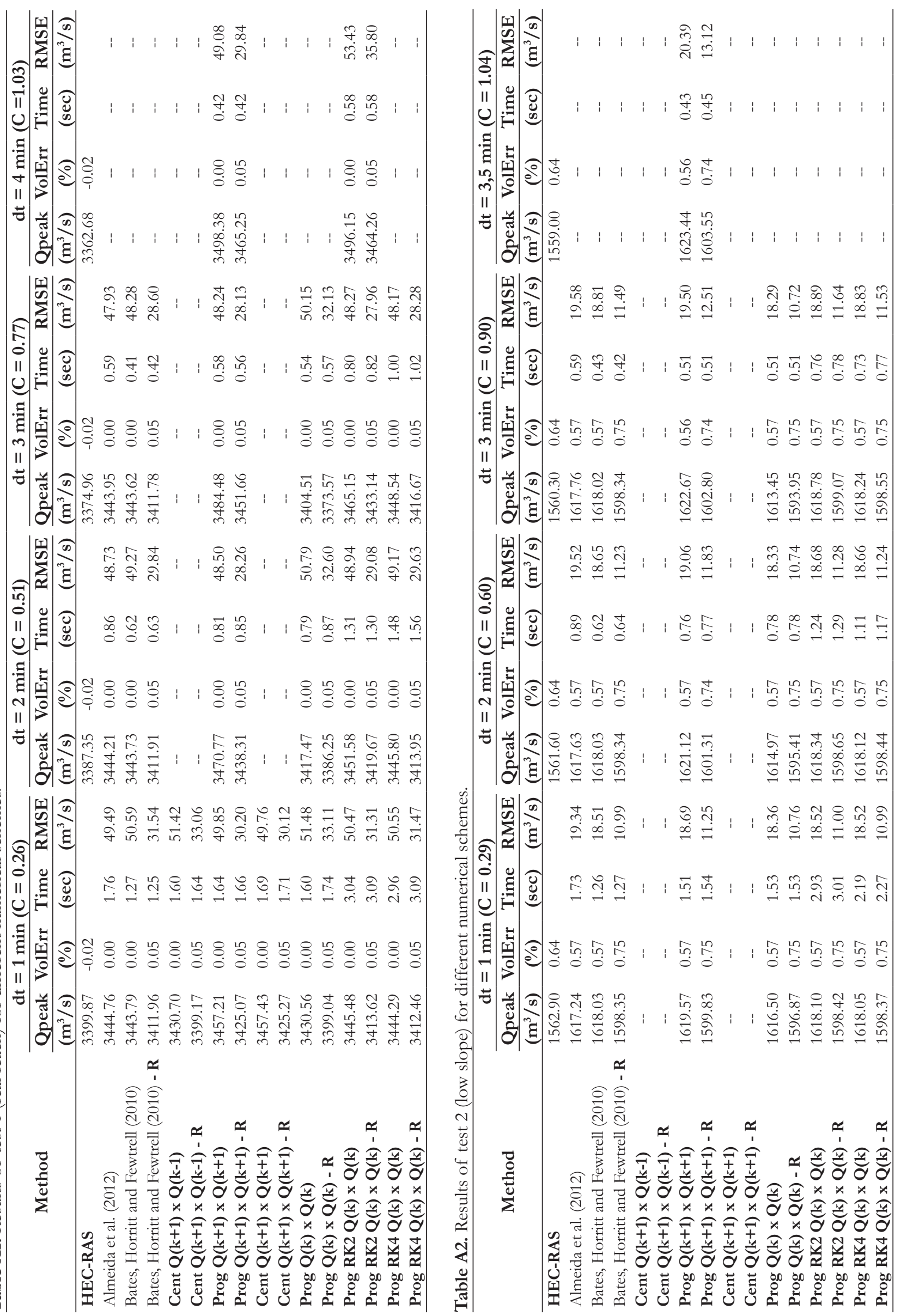

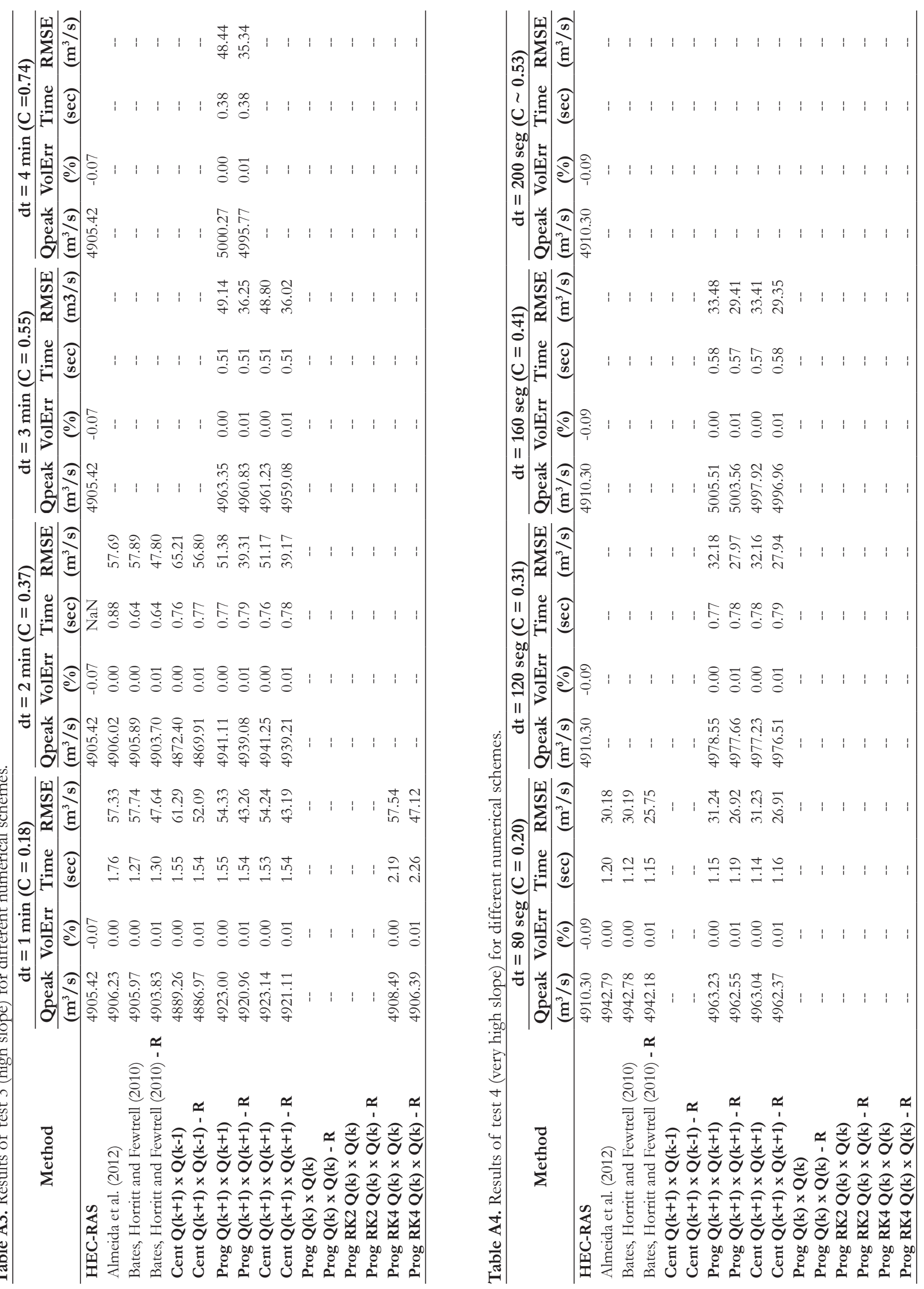

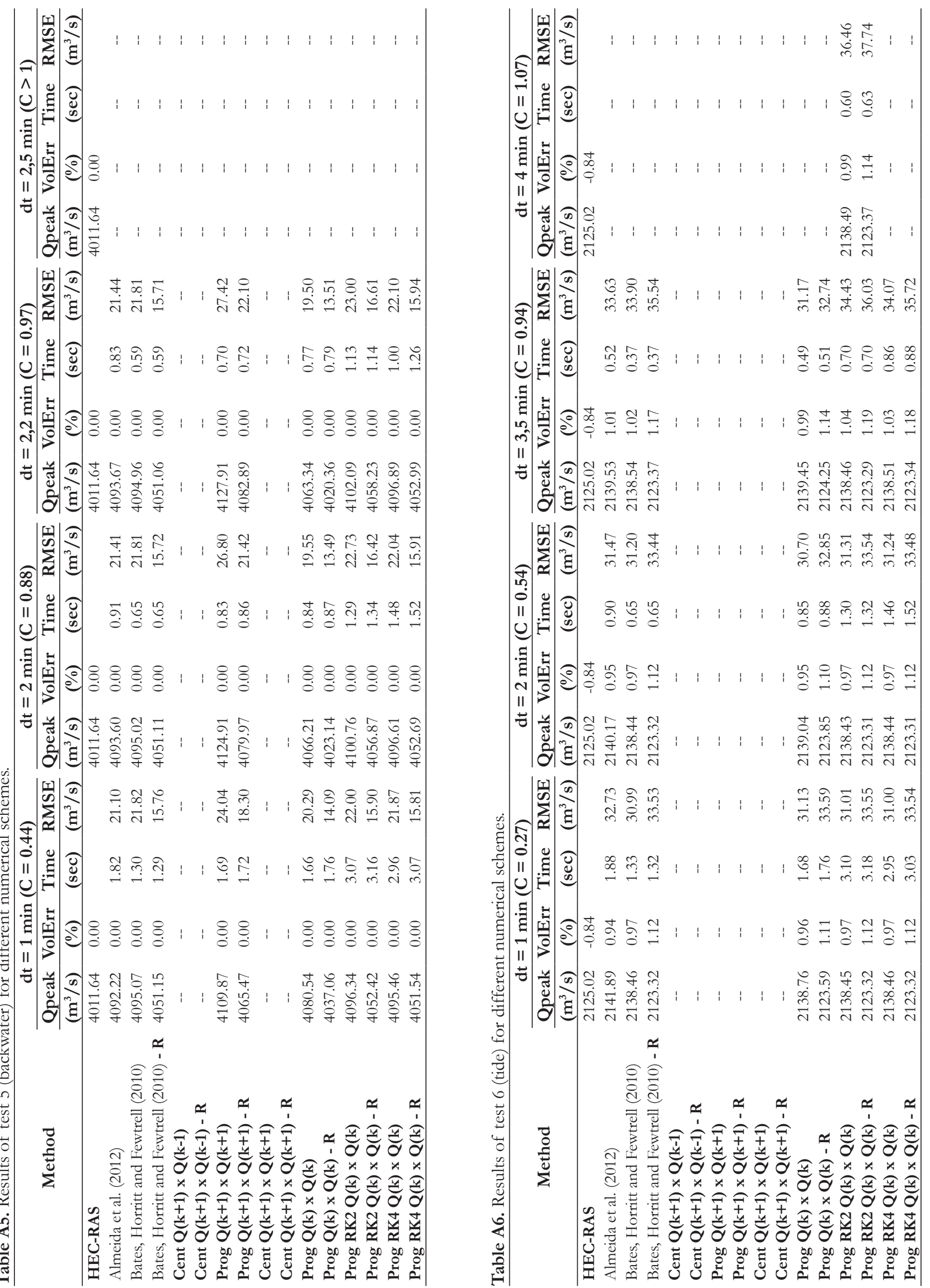